\title{
RESEARCH / INVESTIGACIÓN \\ Cicloturismo como alternativa estratégica para la promoción del turismo sustentable de localidades rurales del Valle de Elqui, Chile

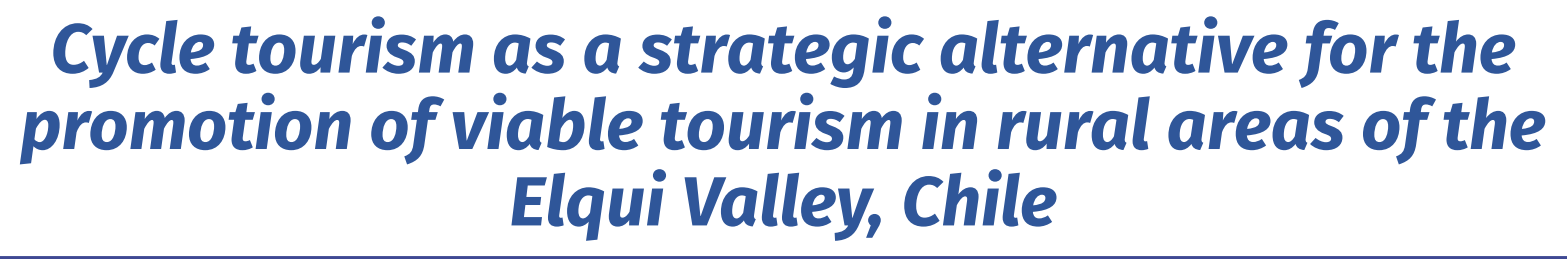

Sebastián Araya P. ${ }^{1}$, Carlos Varas M. ${ }^{2}$.

Resumen: La creciente importancia del Turismo de Intereses Especiales (TIE), impulsado por el aumento de la demanda de actividades de recreación al aire libre, ha generado el desarrollo de nuevos tipos de turismo, basados en el aprovechamiento del medio natural y en estrecho vínculo con el patrimonio cultural. En este trabajo se analiza el desarrollo del cicloturismo como alternativa estratégica para la promoción de un turismo sustentable en localidades rurales de la comuna de Paihuano, Valle del Elqui, Chile. A través de una investigación descriptiva, transeccional y de enfoque mixto con predominancia cualitativa, se analizaron los diversos factores que influyen, tanto positiva como negativamente, en su asentamiento como una opción al turismo tradicional de la zona. La metodología contempló la revisión documental y arqueo bibliográfico, además del desarrollo de entrevistas con autoridades locales; grupo focal con ciclistas de la región, y la aplicación de 48 encuestas a turistas que realizaron cicloturismo en la zona. Los resultados demostraron que la comuna de Paihuano reúne las condiciones naturales, los servicios suplementarios y el nivel de aceptación apropiado de la comunidad y sus visitantes para instaurar la actividad como un recurso turístico alternativo. Sin embargo, se concluye que, para ser considerada una opción viable a las demás actividades turísticas ofrecidas en la zona, requiere de un mayor nivel de compromiso de parte de las autoridades en la promoción de la cultura turística de la localidad, así como mejorar la infraestructura e información necesaria para su implementación y práctica, tales como ciclovías, señaléticas, y tableros informativos, entre otras.

Palabras claves: Turismo de intereses especiales, cicloturismo, turismo sustentable, enfoque mixto.
Abstract: The increasing importance of special interest tourism (SIT), driven by the increased demand for outdoor recreation activities, has generated the development of new types of tourism based on taking advantage of nature and the close connection with cultural heritage. In this study, the development of cycle tourism is analyzed as a strategic alternative for the promotion of viable tourism in rural areas of the commune of Paihuano, Elqui Valley, Chile. This descriptive, cross-sectional and mixed approach study that is predominantly qualitative analyzes the various factors that influence, both positively and negatively, its establishment as an option to the traditional tourism of the area. The methodology included a document review and bibliographic search, in addition to interviews with local authorities, a focus group with cyclists in the region, and the application of 48 surveys to tourists who had participated in cycle tourism in the area. The results showed that the commune of Paihuano meets the natural conditions, the additional services and the appropriate level of acceptance by the community and its visitors to establish the activity as an alternative tourism resource. However, it is concluded that to be considered a viable option to the other tourist activities offered in the area, a greater level of commitment is required from the authorities in promoting the tourism culture of the location, as well as improving the infrastructure and information needed for its implementation and practice, such as cycle paths, signage and informational boards, among others.

Key words: Special interest tourism, cycle tourism, viable tourism, mixed approach.

\section{(Presentado: 19 de noviembre de 2017. Aceptado: 10 de enero de 2018)}

\footnotetext{
1 Magíster en Liderazgo, Dirección Estratégica y Comunicación en las Organizaciones. Profesor Departamento de Ciencias Económicas y Empresariales, Universidad de La Serena, Chile. Email: sarayaquserena.cl

2 Magíster en Recursos Humanos. Profesor Departamento de Ciencias Económicas y Empresariales, Universidad de La Serena. E-mail: cvaras(quserena.cl
} 


\section{INTRODUCCIÓN}

La creciente importancia del Turismo de Intereses Especiales (TIE), impulsado por el aumento de la demanda de actividades de recreación al aire libre, ha generado el desarrollo de nuevos tipos de turismo, basados en el aprovechamiento del medio natural y, también, en estrecho vínculo con el patrimonio cultural (Szmulewicz \& Veloso, 2013).

La comuna de Paihuano es una localidad ubicada en el corazón del Valle de Elqui, en la IV Región de Coquimbo, Chile. Presenta una superficie de $1.533,7 \mathrm{~km}^{2}$, con una población estimada para el año 2015 de 4.492 habitantes, de carácter $100 \%$ rural, dedicada principalmente al turismo y agricultura (Biblioteca del Congreso Nacional, 2015). En la comuna destacan localidades como: Pisco Elqui, Cochiguaz, Alcoguaz, y Montegrande, pueblo que alberga el Museo Casa-Escuela y Mausoleo de la poetisa chilena y Premio Nobel de Literatura: Gabriela Mistral.

La zona, posee una serie de atractivos, referidos a su ubicación y geografía, que han generado un tipo de turismo no convencional, místico y contemplativo. Por esta razón, durante todo el año se reciben turistas y en especial, en las épocas de vacaciones y festivos (Díaz Ortega, 2004), llegándose a reconocer como uno de los lugares con características culturales e históricas únicas, con trascendencia mundial, lo cual ha forjado un atractivo especial para los pueblos que lo conforman.

Uno de los productos turísticos de intereses especiales que presenta gran potencial de desarrollo en la comuna de Paihuano es el cicloturismo, una disciplina no competitiva, que emplea la bicicleta como medio de transporte para efectuar recorridos por sitios de interés turístico con libertad y autonomía (Aragoneses Maroto, 2010). Esta actividad además comprende un modo ecológico de viajar y conocer un territorio, que no exige gran preparación física y ofrece a cambio experiencias que con otros medios de transporte es difícil de lograr, sobre todo cuando se pretende conocer lugares de difícil acceso.

La presente investigación analiza el mercado del cicloturismo como una alternativa estratégica para la promoción de un turismo sustentable para la comuna de Paihuano. Para esto se plantean cuatro objetivos fundamentales.
En primer lugar, se propone indagar las ventajas y desventajas del cicloturismo como actividad turística para la comuna de Paihuano, evaluando los pros y los contras de su desarrollo. En segundo lugar, se describe el perfil del turista que realiza cicloturismo en la zona, a fin de diseñar estrategias focalizadas al cliente del cicloturismo. En tercer lugar, se analiza la oferta turística para el cicloturismo y actividades suplementarias que se desarrollan en la comuna de Paihuano, investigando y recopilando la información sobre los servicios turísticos determinantes de la industria turística local. En cuarto lugar, se diagnostica la aceptación del cicloturismo como producto turístico para la comuna a través de las perspectivas gubernamental, empresarial y de mercado.

El turismo sustentable puede jugar un rol muy importante en el desarrollo de las comunidades rurales, especialmente en áreas en las que abundan los recursos naturales y culturales (Covarrubias Ramírez, Vargas Vásquez, \& Rodríguez Herrera, 2010). En particular se espera que los hallazgos encontrados puedan contribuir al crecimiento y expansión del turismo regional y a la regeneración económica y social de áreas rurales, al incorporar nuevas formas de desarrollo y nuevos recursos turísticos alineados con las crecientes tendencias de vida sana y sustentabilidad, en una de las zonas de mayor afluencia turística de la Región de Coquimbo.

El siguiente artículo se organiza en cuatro apartados. Inicialmente, expone las referencias teóricas básicas que sustentan el estudio, luego describe la metodología utilizada para el logro de los objetivos de investigación, continúa con la exposición de los resultados y hallazgos y, por último, se presentan las conclusiones generales respecto al potencial desarrollo del cicloturismo en el área de estudio.

\section{REVISIÓN BIBLIOGRÁFICA}

El turismo es un fenómeno social, cultural y económico relacionado con el movimiento de las personas a sitios que se encuentran fuera de su lugar de residencia habitual por motivos personales, de negocios o profesionales (Morère Molinero \& Perelló Oliver, 2013), cuyo desarrollo tiene efectos en la economía, en el entorno natural y en 
las zonas edificadas, en la población local de los lugares visitados y en los propios visitantes. Es debido a esto, que la amplia gama y variedad de factores de producción requeridos para crear los bienes y servicios adquiridos por los visitantes y al amplio espectro de agentes involucrados o afectados por el turismo, adopten un enfoque global del desarrollo, la gestión y la supervisión del turismo.

Como indica Moral (2016), hoy por hoy, existe la necesidad de propiciar un desarrollo turístico sostenible de los destinos, lo que implica la incorporación de un conjunto de actuaciones dirigidas a garantizar la preservación de los recursos naturales, la autenticidad cultural y la rentabilidad de la actividad turística. Este enfoque, como propone Noguera (2016), es muy recomendable con miras a la formulación y puesta en práctica de políticas de turismo nacionales y locales, así como de acuerdos internacionales u otros procesos en materia de turismo.

La sostenibilidad del destino turístico se transforma en un factor diferenciador clave que impacta la competitividad y sienta las bases de la conservación del medio natural para las futuras generaciones. Puccio \& Grana (2008) destacan la importancia de la innovación para la competitividad del sector turístico, subrayando que, a mayor diferenciación, mayor cuota de innovación es por ello que la capacidad de innovación que desarrolla un destino se constituye en un parámetro a tener en cuenta al momento de evaluar y diagnosticar la competitividad de los mismos. Maráková \& Medved'ová, (2016) enfatizan que impulsar la innovación en los destinos turísticos se encuentra entre los factores que más influyen en el desarrollo sostenible de éste.

En este punto es relevante destacar tanto por su nivel de aceptación a nivel normativo como científico en este ámbito de la investigación turística, la definición propuesta por la Organización Mundial del Turismo (OMT) que define al turismo sostenible como aquel turismo que tenga plenamente en cuenta sus impactos económicos, sociales y ambientales actuales y futuros, las necesidades de los visitantes, la industria, el medio ambiente y las comunidades locales (UNEP-WTO, 2005).

En la actividad turística existen diversas subcategorías o disciplinas distintivas. Una de ellas, es el Turismo de Intereses Especiales (TIE), el cual se sustenta y proyecta bási- camente en los recursos naturales, la cultura y la historia de las comunidades en su entorno territorial, haciendo de ellos un producto alternativo de alta demanda, ante la creciente humanización del servicio. Es una forma de hacer turismo sustentado en la cultura e identidad de una región en específico. Esta actividad busca centrar un destino y ligarlo a una actividad específica del turista, como por ejemplo lo son en Chile la nieve y deportes acuáticos en la zona de La Araucanía, el turismo ligado a la naturaleza en la zona de la Patagonia y las Torres del Paine, o el rescate de tradiciones históricas y patrimoniales en destinos como el Altiplano o la Pampa. Espinosa, Llancaman \& Sandoval (2014) postulan que con el turismo de intereses especiales se intenta aumentar el número de ofertas más sofisticadas y que involucran mayor gasto del turista, presentándose como una alternativa de desarrollo para regiones con una gran diversidad y riqueza de este tipo de recursos. Dentro de estos tipos de turismo destacan el turismo cultural, turismo rural y el turismo aventura.

El turismo cultural es una forma de realizar turismo, motivada por conocer, experimentar y comprender distintas culturas, formas de vida, costumbres, tradiciones, monumentos, sitios históricos, arte, arquitectura y festividades que caracterizan a una sociedad y su gente, que reflejan la identidad de un destino (Servicio Nacional de Turismo, 2014). El ICOMOS (Internacional Council of Sites and Monuments) define el turismo cultural, siguiendo las directrices de la World Trade Organization (WTO), como un movimiento de personas esencialmente por una motivación cultural, tal como el viaje de estudios, representaciones artísticas, festivales u otros eventos culturales, visitas a lugares y monumentos, folklore, arte o peregrinación (Santana Talavera, 2003). También se refiere a las actividades que tienen lugar en un ambiente rural, con las costumbres y actividades que se viven en los ambientes lejos de las ciudades y áreas industrializadas, tales como pueblos, granjas, etc.

Cabe destacar que el turismo rural puede no estar directamente relacionado con la actividad agrícola y puede ser organizado por personas que no son agricultores (Casas Manríquez, 2004). De esta forma, el concepto de turismo rural recoge diversas definiciones, como la clásica expuesta por Gannon (1994) que define al Turismo rural como toda la gama de actividades y amenidades provistas por campesinos y personas rurales para atraer turistas a su 
área, para así generar un ingreso extra para sus negocios y la de (García, 1996) quien afirma que es aquella actividad que se basa en el desarrollo, aprovechamiento y disfrute de nuevos productos presentes en el mercado e íntimamente relacionados con el medio rural.

El turismo aventura, como parte del turismo rural, conforma actividades específicas que utilizan el entorno o medio natural como soporte físico y recurso para producir en los turistas determinadas emociones y sensaciones de descubrimiento y de exploración, que implican cierto empeño, actividad física y riesgo controlado (Ley $N^{\circ} 20423,2010$ ).

Dentro de la actividad que comprende tanto al turismo de intereses especiales como al turismo aventura y cultural se encuentra el cicloturismo, una actividad que de acuerdo a la Norma Chilena Oficial NCH 3050.of 2007 del Sernatur, se define como una actividad turística recreativa que consiste en realizar recorridos en bicicletas adecuadas para la actividad, en sectores urbanos o rurales, en carreteras o fuera de éstas, de interés paisajístico, cultural o medioambiental, en las modalidades de roadbike, citybike, mountainbike, touringbike y otras.

El uso de la bicicleta cuenta con diversos beneficios generales derivados de su práctica (Cox, 2013; Ilieș, Herman, Dehoorne, \& Măduța, 2013). Reduce la contaminación del ruido proveniente del transporte vehicular, principal fuente emisora de este contaminante dada la necesidad de movilización diaria de las personas y de los requerimientos de transporte para soporte del sistema industrial, comercial, de servicios y administrativo (Ramírez González \& Domínguez Calle, 2011). No se emiten contaminantes a la atmósfera, principalmente los relacionados a la combustión del petróleo, una de las mayores causales de la denominada contaminación ambiental moderna (Cherni, 2001), pues emite entre un $50 \%$ y un $80 \%$ menos gases de efecto invernadero en relación al transporte tradicional.

Se consume menos espacio público y en consecuencia se reduce la congestión vehicular y los embotellamientos. Contribuye a reducir el sedentarismo, la obesidad y otras afecciones de la salud humana (Eltit Neumann, 2011), constituyéndose como un determinante importante de la longevidad de quienes lo practican habitualmente (Matthews et al., 2007) y consolida el desarrollo de un ocio saludable y sostenible respetuoso con el entorno. Al respecto, el estudio desarrollado Gonçalves-Junior, Corrêa, da Silva Carmo, \& Toro Arévalo, (2016), concluye que la utilización de la bicicleta puede favorecer acciones educativas orientadas hacia la promoción del ocio crítico y de la educación ambiental, revelando que la apertura a la que se expone el cicloturista provoca actitudes empáticas entre el grupo y las personas que habitan las localidades recorridas y una vivencia más profunda del medio ambiente.

Asimismo, la bicicleta es un medio de transporte económico y popular, más barato de adquirir, mantener, guardar, utilizar y que no necesita de ningún permiso especial para su uso (Mató \& Troyano, 2014). De esta forma, el cicloturismo, otorga la posibilidad de recorrer caminos de difícil acceso para cualquier otro tipo de transporte. Permite tener un contacto directo con la naturaleza y con pueblos y ciudades que se encuentran en la ruta. También como destacan, Herrera \& Cortés (2006), es una forma barata de hacer turismo, que puede ser realizada por aficionados que generalmente contratan un tour operador con un itinerario ya establecido, o por profesionales que trazan sus propias rutas y manejan los conocimientos de mantención de la bicicleta y de seguridad.

Existen variadas experiencias exitosas en el mundo respeto del uso del cicloturismo como actividad que impulsa un turismo sustentable (La Patagonia y Tierra del Fuego, en Argentina y Chile; Pacific Coast Highway, en Estados Unidos; Shimanami Kaido, en Japón; Donauradweg, en Alemania, Austria y Hungría; Munda Biddi en Australia y la ruta internacional EuroVelo, que con doce rutas internacionales de largas distancias cruza todo el continente). Cabe destacar, además, que en el contexto económico y social actual apremiante, el aumento de los precios de los combustibles, de las emisiones de gases de efecto invernadero del transporte y, sobre todo, del incremento de los niveles de obesidad, llevan a plantearse entonces, cuáles son las condiciones que posibilitan que un destino tenga éxito en la implementación y desarrollo de una actividad turística sostenible, que proporciona soluciones concretas a los problemas antes mencionados, situación que se aborda en este estudio, mediante el análisis del cicloturismo en la comuna de Paihuano. 


\section{ÁREA DE ESTUDIO}

La comuna de Paihuano (o Paiguano) se encuentra ubicada en la provincia del Elqui, IV región de Coquimbo. La cual se encuentra a $557,8 \mathrm{~km}$ de Santiago y a $87,5 \mathrm{~km}$ al este de la ciudad de La Serena (capital regional). Está compuesta por ocho distritos: Paihuano, La Quebrada, La Bajada, Quebrada de Pinto, Montegrande, Alcohuaz, Pisco Elqui y Jarillas.

Los límites de la Comuna de Paihuano fueron asignados por decreto del 01 de septiembre de 1853 y del 27 de marzo de 1863, siendo éstos los siguientes: Al Norte con la comuna de Vicuña; al Sur con la comuna de Río Hurtado, provincia de Limarí y República Argentina; al Este con la comuna de Vicuña y República Argentina; y al Oeste con la comuna de Río Hurtado y Vicuña. Su principal actividad económica es la agricultura, con el cultivo de uva de mesa de exportación y pisquera; luego la sigue la industria pisquera y la actividad turística (Díaz Ortega, 2004).

El territorio se distribuye en un área de $1.533,7 \mathrm{~km}^{2}$, con una población estimada al año 2015 de 4.256 habitantes. Tiene un clima de Precordillera, seco y templado. De los 1.000 a los $2.000 \mathrm{mts}$. de altura, la humedad va de los $30 \%$ a un $15 \%$, la temperatura media es de $24^{\circ}$ y; la Pluviometría de $100 \mathrm{~mm}$. Posee dos valles de importancia, como lo son el Valle de Cochiguaz y el Valle de Alcohuaz, que dan origen a dos afluentes de aguas cristalinas y puras, que albergan una variada fauna. En sus localidades se puede encontrar una variada oferta de alojamientos turísticos, también lugares para acampar y realizar paseos diarios. Además, existe una variada oferta para aquellos turistas que desean meditar, relajarse o conocer más de cerca del arte esotérico. En ambos valles se pueden realizar actividades tales como caminatas por diferentes senderos, escalar cerros y altas cumbres o pasear en bicicleta. Las vías de acceso a las distintas localidades se transforman en caminos pintorescos que permiten apreciar la naturaleza y la arquitectura de la comuna.

El acceso a la comuna, es por ruta $41-\mathrm{CH}$, (conocida como D-41), en el kilómetro 80, la cual sube por la cordillera hasta llegar al Paso Agua Negra en la frontera con Argentina. Esta ruta goza de buenas condiciones de mantención, la que ejecuta la Dirección Provincial de Vialidad.
En Paihuano, el análisis de distribución urbana rural no se puede asimilar al resto de las comunas de Chile por cuanto, si bien existen límites urbanos, los centros poblados, por sus características no se consideran urbanas a los parámetros del Instituto Nacional de Estadísticas (INE).

La Figura 1 ilustra la ubicación geográfica de las principales localidades de la comuna de Paihuano (Alcohuaz, Cochiguaz, Montegrande, Paihuano y Pisco Elqui), objetos de estudio en este trabajo de investigación.

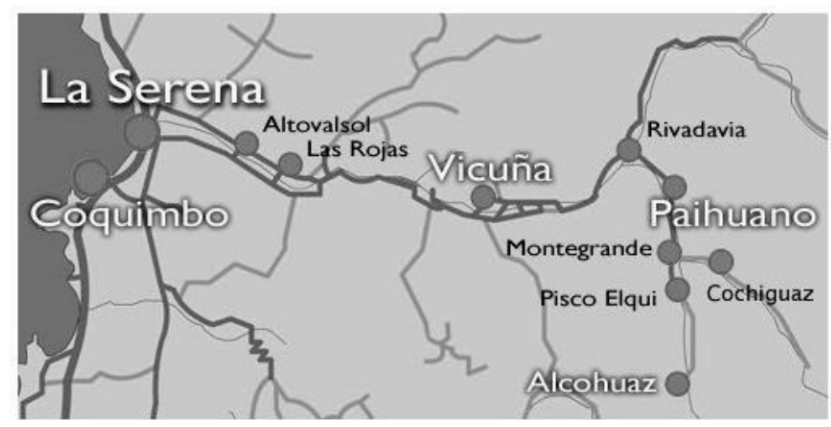

Figura 1. Ubicación geográfica de las principales localidades de la comuna de Paihuano (Elaboración propia en base a http://www.premiumwines.com.br)

\section{METODOLOGÍA}

La investigación utilizó un diseño no experimental, de enfoque mixto con predominancia cualitativa, de tipo descriptiva, y alcance transeccional, orientada en analizar el potencial de desarrollo del cicloturismo como actividad turística sustentable en la comuna de Paihuano. Para el levantamiento de la información, y acorde al enfoque mixto del estudio, se utilizaron tres técnicas de investigación: grupo focal, entrevistas a informantes claves y un cuestionario.

El grupo focal tuvo por meta identificar los requerimientos para una ruta ciclística atractiva al turista que visita la localidad de Paihuano. Se llevó a cabo con once miembros del Club deportivo Mountain Fly de la IV Región de 
Coquimbo, dado su experiencia en el ciclismo y conocimiento de la zona. La dinámica de grupo se realizó el día 19 de noviembre de 2016, en la Bahía de Guanaqueros de la Cuarta región de Coquimbo y contó con la participación de un ingeniero comercial que realizó el papel de mediador. Fue elaborada una guía con el fin de dirigir la reunión y mantener la línea del objetivo del estudio, para lo cual se abordaron preguntas referentes a las rutas más visitadas en el Valle de Elqui, los atributos destacados de una ruta ciclística idónea, los servicios necesarios para complementar la actividad y los requerimientos específicos para su ejecución en la comuna de Paihuano. La duración de la actividad fue de 80 minutos aproximadamente, fue grabada en su totalidad y transcrita electrónicamente.

Las entrevistas a expertos fueron encauzadas al diagnóstico del nivel de aceptación del cicloturismo en la comuna de Paihuano. Fueron seleccionados tópicos generales sobre dicho tema para orientar las entrevistas de los participantes. Se realizaron tres entrevistas enfocadas a los informantes claves del estudio que fueron: el alcalde de Paihuano (autoridad máxima de la comuna), el director regional de Servicio Natural de Turismo - Sernatur (organismo público encargado de promover y difundir el desarrollo de la actividad turística de Chile) y la dueña de la empresa Turismo Migrantes (principal tour operador de Paihuano). Los encuentros tuvieron una duración promedio de una hora y se desarrollaron en las dependencias de los entrevistados. Por último, se aplicó un cuestionario (en español e inglés) de 20 preguntas cerradas para caracterizar el perfil y gustos del turista que practica cicloturismo en la comuna. La población objetivo fue definida en función de un universo móvil de 577 turistas y calculada en base a los registros contables de la empresa Turismo Migrantes durante el año 2015, obteniendo un tamaño muestral de 48 turistas que realizaron cicloturismo en Paihuano. El instrumento se aplicó de manera presencial, durante los días 8,9 y 10 de octubre de 2016. Cabe señalar que los resultados del análisis de las encuestas fueron obtenidos mediante el software PASW Statistics 18.0 para MS Windows, a través del cómputo de tablas y gráficas de frecuencias.

\section{RESULTADOS Y DISCUSIÓN}

A continuación, se presentan los principales resultados del estudio, agrupados en cuatro secciones: (i) ventajas y desventajas del cicloturismo para la comuna de Paihuano; (ii) perfil del turista que realiza cicloturismo en la zona; (iii) aceptación del cicloturismo como producto turístico para la comuna; y (iv) descripción de la oferta turística y actividades suplementarias para el cicloturismo en la localidad.

\section{Ventajas y desventajas del cicloturismo para la comuna de Paihuano}

El cicloturismo como una actividad arraigada al sector turístico demuestra diversos ámbitos y aspectos que presentan ventajas y desventajas. Primero, en cuanto a las ventajas del cicloturismo como actividad turística para la comuna de Paihuano se pueden mencionar:

- Desarrollo de una oferta turística ecológica: que amplía la gama de servicios tradicionales bajo un concepto de turismo sustentable y ecológico, acorde a las nuevas tendencias mundiales enfocadas en mejorar las condiciones de bienestar y de vida de una manera sostenible para las generaciones presentes y futuras (Verheugen, 2005).

- Generación de nuevos retornos económicos directos e indirectos: pues crea nuevos empleos y ayuda a fijar la población local. Dentro de los beneficios económicos se contabiliza el gasto en alojamiento, alimentación, compras, transporte o actividades locales (entrada a museos, elementos patrimoniales, eventos, etc.), junto con los demás gastos producidos normalmente antes del viaje, como el gasto en el desplazamiento hasta el itinerario o la adquisición de guías. Cabe mencionar que existe un estudio que señala un coeficiente multiplicador de 1,57 sobre el impacto económico de la actividad cicloturística (Zovko, 2013), lo que implica que las cantidades expresadas como impacto económico directo deberían ser multiplicadas por tal factor. Además, el cicloturismo puede ser una actividad rentable, porque permite la organización de eventos, competiciones y torneos ciclistas (Gozner, 2015).

- Bajos requerimientos de inversión: porque se pueden reutilizar antiguas infraestructuras, caminos o senderos naturales existentes de la comuna, así como aprovechar el espacio vial compartido con caminos de muy baja intensidad de tráfico. Mató \& Troyano (2014) 
mencionan que la amortización de la inversión es rápida (dentro de 1 año). Además, para un tour operador el costo de mantención de las bicicletas es mínimo en comparación a otros tipos de medios de transporte como: automóviles, motocicletas, carretas o caballos. De esta manera la bicicleta es un medio de transporte comparativamente rentable en términos de inversión y mantención.

- Condiciones naturales y culturales adecuadas: El Valle de Elqui, es reconocido mundialmente por sus cielos diáfanos, clima privilegiado y paisajes únicos, que le brinda ventajas comparativas para la práctica del cicloturismo durante todo el año. Según el análisis del grupo focal, permitiría acceder, fácilmente, a comunidades alejadas o de difícil ingreso para el tránsito de vehículos pequeños y sin doble tracción, como lo son los pueblos artesanales de Alcohuaz y Horcón.

\section{Entre las desventajas, se encuentran:}

- Poca implicación de tour-operadores y proveedores de cicloturismo, los cuales funcionan de manera independiente y no organizada.

- Falta de acceso a la información sobre rutas ciclísticas o servicios complementarios como hospedaje, restaurantes, elementos patrimoniales, etc., lo que dificulta la buena recepción y atención del turista que visita la zona. Este desconocimiento se evidencia en la comunidad y también por parte de los entes de promoción y de las oficinas de turismo.

- Escaso apoyo de parte de las autoridades locales y organismos gubernamentales para el desarrollo del cicloturismo. Especialmente en materia de promoción y de inversiones en infraestructura. Por ejemplo, en Europa, el éxito de su práctica se supedita en gran parte a existe un apoyo económico claro de la Unión Europea (UE) a las iniciativas vinculadas con el cicloturismo como los son: "Iron curtain trail", "North sea cycle route", "Greenways for Tour", "Greenways Product", Pirinexus, o el desarrollo de itinerarios cicloturistas como es el caso de las Vías Verdes (greenways) y de Eurovelo, una red europea de $70.000 \mathrm{~km}$ de rutas ciclistas.

- Por su condición de comuna rural poco intervenida, no cuenta con la infraestructura adecuada (ciclovías, señaléticas, tableros informativos con las rutas) para desarrollar la disciplina. Tampoco dispone de zonas de resguardo del calor o puntos de descanso en ruta y se aprecia una escasa adaptación de los alojamientos a las necesidades de los cicloturistas.

- Falta de rutas ciclísticas establecidas que permitan darle formalidad y continuidad a la actividad.

- El cicloturismo implica riesgos de accidentes, por lo cual esta actividad es categorizada, en la normativa chilena, como turismo aventura, lo que obliga a obtener al oferente una autorización y certificación especial de parte de la autoridad respectiva (SERNATUR).

\section{Perfil del turista que realiza cicloturismo en la zona}

Los resultados de la encuesta revelaron que la mayoría de los visitantes que practican cicloturismo son de sexo masculino (72,9\%), poseen una edad promedio de 30 años, son de origen nacional $(68,75 \%)$ y realizan el viaje con amigos $(39,6 \%)$ o junto a un familiar $(31,3 \%)$. Los turistas extranjeros provienen principalmente de Argentina, Colombia, Estados Unidos y España (Tabla 1).

Los encuestados declararon que el reconocimiento mundial que tiene el Valle de Elqui fue el motivo principal que los llevó a visitar la zona (49,70\%) y que volverían a hacerlo (83,3\%). En cuanto a los hábitos del visitante se observó que utilizan como medio de transporte el vehículo propio (66,7\%); pernoctan un tiempo promedio de 3 días (68,8\%); utilizan el efectivo como medio de pago durante su estadía (72,9\%); registrando un gasto promedio que oscila los USD 75 por visita $(60,4 \%)$ y que la mayoría no habían practicado el cicloturismo anteriormente (54,2\%). Respecto a esto, destaca que gran parte de los turistas nacionales no habían realizado esta actividad antes (60,6\%), mientras que los turistas extranjeros ya contaban, en su mayoría, con experiencia previa (60\%). Los turistas internacionales que habían practicado la actividad, a su vez, explicaron haberlo hecho en Argentina, Brasil, Colombia, Ecuador, España, Estados Unidos, Francia, México y Chile (Santiago y Viña del Mar). Por otra parte, al revisar el propósito de los turistas por practicar el cicloturismo, se reveló que lo realizaban con el fin de conocer la zona o localidad que visitan $(59,1 \%)$ o de lograr una conexión con la naturaleza $(36,4 \%)$. Al respecto, destaca que el turista nacional, presentó como motivo principal el de conocer el lugar que visita, mientras que el turista extranjero para lograr una 
conexión con el medio ambiente que lo rodea. Además, los visitantes, independientemente de su nacionalidad, indicaron que preferían realizar esta actividad por un tiempo superior a dos horas $(60,4 \%)$ y en una ruta establecida
(81,8\%), que tenga la seguridad y señalización correspondiente. Finalmente, casi la totalidad de los encuestados declaró pagar entre USD 3,5 y USD 8,5 por el arriendo de una bicicleta $(91,7 \%)$.

Tabla 1. Perfil del turista que practica cicloturismo en Paihuano.

\begin{tabular}{|c|c|c|c|c|c|}
\hline $\mathbf{N}^{\circ}$ & Pregunta & & epuestas (Porcent & & \\
\hline$\overline{1}$ & Sexo & $\begin{array}{l}\text { Masculino } \\
72,9 \%\end{array}$ & $\begin{array}{c}\text { Femenino } \\
27,1 \%\end{array}$ & & \\
\hline 2 & Nacionalidad & $\begin{array}{c}\text { Nacional } \\
68,7 \% \\
\end{array}$ & $\begin{array}{c}\text { Extranjero } \\
31,3 \%\end{array}$ & & \\
\hline 3 & Motivo visita & $\begin{array}{c}\text { Vacaciones } \\
79,2 \%\end{array}$ & $\begin{array}{c}\text { Visita Cultural } \\
16,7 \%\end{array}$ & $\begin{array}{c}\text { Visita Familiar } \\
4,2 \%\end{array}$ & \\
\hline 4 & Como supo del Valle & $\begin{array}{c}\text { Reconocimiento } \\
\text { mundial } \\
47,9 \% \\
\end{array}$ & $\begin{array}{c}\text { Publicidad } \\
\text { por Internet } \\
10,4 \%\end{array}$ & $\begin{array}{c}\text { Recomendación } \\
\text { de un conocido } \\
39,6 \% \\
\end{array}$ & $\begin{array}{c}\text { Agencia de } \\
\text { Viajes } \\
2,1 \% \\
\end{array}$ \\
\hline 5 & Frecuencia visitas & $\begin{array}{c}\text { Primera vez } \\
52,1 \%\end{array}$ & $\begin{array}{c}\text { Segunda vez } \\
20,8 \%\end{array}$ & $\begin{array}{c}\text { Más de dos veces } \\
27,1 \%\end{array}$ & \\
\hline 6 & Con quien realiza el viaje & $\begin{array}{c}\text { Solitario } \\
4,2 \%\end{array}$ & $\begin{array}{c}\text { En pareja } \\
25 \%\end{array}$ & $\begin{array}{l}\text { Familia } \\
31,3 \%\end{array}$ & $\begin{array}{l}\text { Amigos } \\
39,6 \%\end{array}$ \\
\hline 7 & Volvería a visitar la zona & $\begin{array}{c}\text { Sí } \\
83,3 \%\end{array}$ & $\begin{array}{c}\text { No } \\
16,7 \% \\
\end{array}$ & & \\
\hline 8 & Medio de transporte & $\begin{array}{c}\text { Vehículo } \\
\text { propio } \\
66,7 \%\end{array}$ & $\begin{array}{c}\text { Vehículo } \\
\text { arrendado } \\
14,6 \%\end{array}$ & $\begin{array}{c}\text { Bus } \\
\text { (transporte público) } \\
18,8 \%\end{array}$ & \\
\hline 9 & Medio de pago & $\begin{array}{c}\text { Efectivo } \\
72,9 \% \\
\end{array}$ & $\begin{array}{l}\text { Débito } \\
20,8 \% \\
\end{array}$ & $\begin{array}{c}\text { Crédito } \\
6,3 \% \\
\end{array}$ & \\
\hline 10 & Gasto promedio & $\begin{array}{c}<\text { USD } 50 \\
39,6 \%\end{array}$ & $\begin{array}{c}\text { USD } 50-100 \\
60,4 \%\end{array}$ & $\begin{array}{c}\text { > USD } 100 \\
-\end{array}$ & \\
\hline 11 & Anda en bicicleta & $\begin{array}{c}\text { Sí } \\
87,5 \%\end{array}$ & $\begin{array}{c}\text { No } \\
12,5 \%\end{array}$ & & \\
\hline 12 & Pernoctación & $\begin{array}{c}\text { Sí } \\
68,8 \% \\
\end{array}$ & $\begin{array}{c}\text { No } \\
31,2 \%\end{array}$ & & \\
\hline 13 & Ha realizado cicloturismo & $\begin{array}{c}\text { Sí } \\
45,8 \% \\
\end{array}$ & $\begin{array}{c}\text { No } \\
54,2 \%\end{array}$ & & \\
\hline 14 & $\begin{array}{l}\text { Motivo para } \\
\text { practicarlo }\end{array}$ & $\begin{array}{c}\text { Conexión naturaleza } \\
36,4 \% \\
\end{array}$ & $\begin{array}{c}\text { Vivir una vida sana } \\
4,5 \%\end{array}$ & $\begin{array}{c}\text { Conocer la localidad } \\
59,1 \% \\
\end{array}$ & \\
\hline 15 & Como prefiere realizarlo & $\begin{array}{c}\text { En ruta } \\
\text { establecida } \\
81,8 \% \\
\end{array}$ & $\begin{array}{c}\text { En ruta sin camino } \\
\text { establecido } \\
18,2 \%\end{array}$ & $\begin{array}{c}\text { En el camino } \\
\text { para automóviles } \\
-\end{array}$ & \\
\hline 16 & Tiempo haciendo ruta & $\begin{array}{c}\text { Una hora } \\
-\end{array}$ & $\begin{array}{c}\text { Dos horas } \\
39,6 \%\end{array}$ & $\begin{array}{c}\text { Más de dos horas } \\
60,4 \% \\
\end{array}$ & \\
\hline$\overline{17}$ & Arriendo de bicicletas & $\begin{array}{c}<\text { USD 3,5 } \\
8,3 \%\end{array}$ & $\begin{array}{c}\text { USD 3,5 - 8,5 } \\
91,7 \%\end{array}$ & $\begin{array}{c}>\text { USD } 8,5 \\
-\end{array}$ & \\
\hline
\end{tabular}

Fuente: Elaboración propia. 


\section{Oferta turística para el cicloturismo y actividades re- lacionadas en la comuna de Paihuano}

La comuna de Paihuano se caracteriza por sus atractivos tanto naturales como culturales, los cuales han ayudado a desarrollar la comuna en sus distintos aspectos. La localidad cuenta con un clima precordillerano, seco y templado en dos valles de gran importancia, como lo son el valle de Cochiguaz y el valle de Alcohuaz, los cuales dan origen a dos afluentes de aguas cristalinas y puras, que albergan una variada fauna, el río que lleva el nombre del valle Cochiguaz y el otro es el Estero Derecho.

Dentro de estos valles se encuentran los distintos pueblos que junto a su historia y tradiciones logran exhibir rasgos únicos. Este paisaje y características propias de la comuna proporcionan un atractivo influyente en la llegada de turistas a la localidad y de sus alrededores, llegando a ser la segunda fuente de ingresos para la comuna, después de la actividad agrícola. En cuanto a la oferta turística, se toma en cuenta a las empresas que están registradas en el Sernatur, debido a las normas y exigencias en calidad y servicio que esta institución debe mantener en cada uno de estos establecimientos o servicios propiamente tal. A continuación, se describen los distintos servicios turísticos de la comuna de Paihuano, considerados esenciales para la implantación del cicloturismo como un recurso turístico estratégico.

- Servicios de alojamiento en la comuna de Paihuano: Actualmente en la Comuna de Paihuano existen 74 empresas de alojamiento turístico, de las cuales un 63,5\% están registradas en el SERNATUR. El rubro de alojamiento turístico en la comuna se compone por nueve categorías distintivas del servicio: hotel, apart hotel, hostal, residencia, cabaña, camping, centro de turismo de naturaleza o lodge, departamento turístico y bed and breakfast. Dentro de este registro existe solo una empresa en la zona que cuenta con el Sello de Calidad Turística (Turismo Migrantes). La clasificación de los diferentes alojamientos organizados por ubicación geográfica se ilustra en la Figura 2, donde se aprecia que la mayor concentración de éstos se presenta en el pueblo de Pisco Elqui, seguido por Montegrande, Alcohuaz y Paihuano.

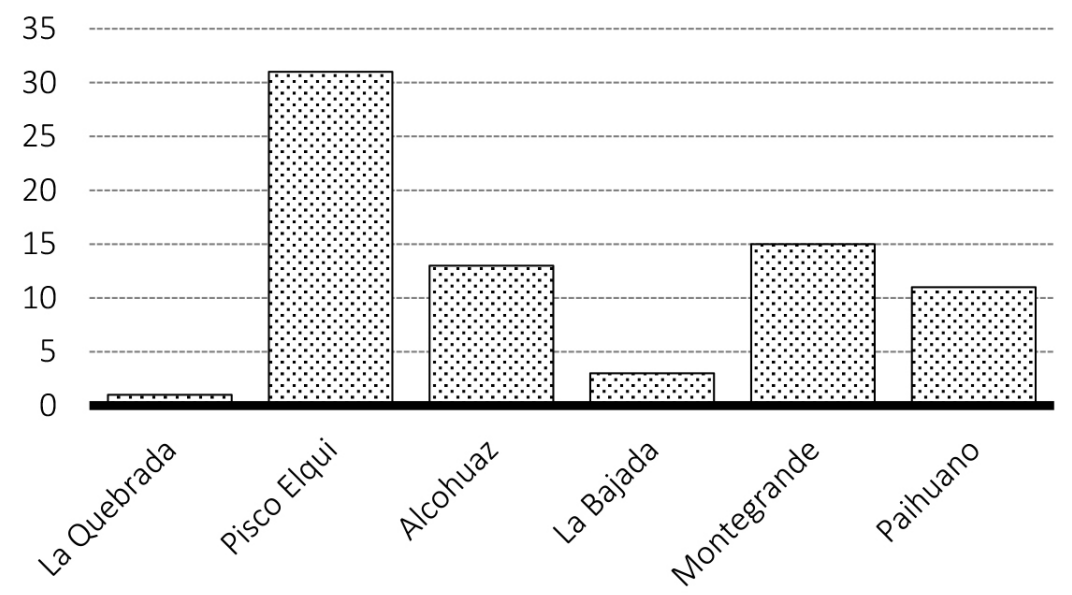

Figura 2. Cantidad de alojamientos en la Comuna de Paihuano. Fuente: Elaboración propia, en base a datos del SERNATUR.

Debido a que la comuna de Paihuano es un sector rural, con valles y ríos que la atraviesan, es que los alojamientos se componen mayoritariamente de cabañas (50\%) y camping (20,2\%), véase la Figura 3. Además, del total de cabañas de la comuna, el pueblo de Pisco Elqui posee el $32,4 \%$, seguido de Alcohuaz (24,3\%) y Paihuano (21,6\%). 


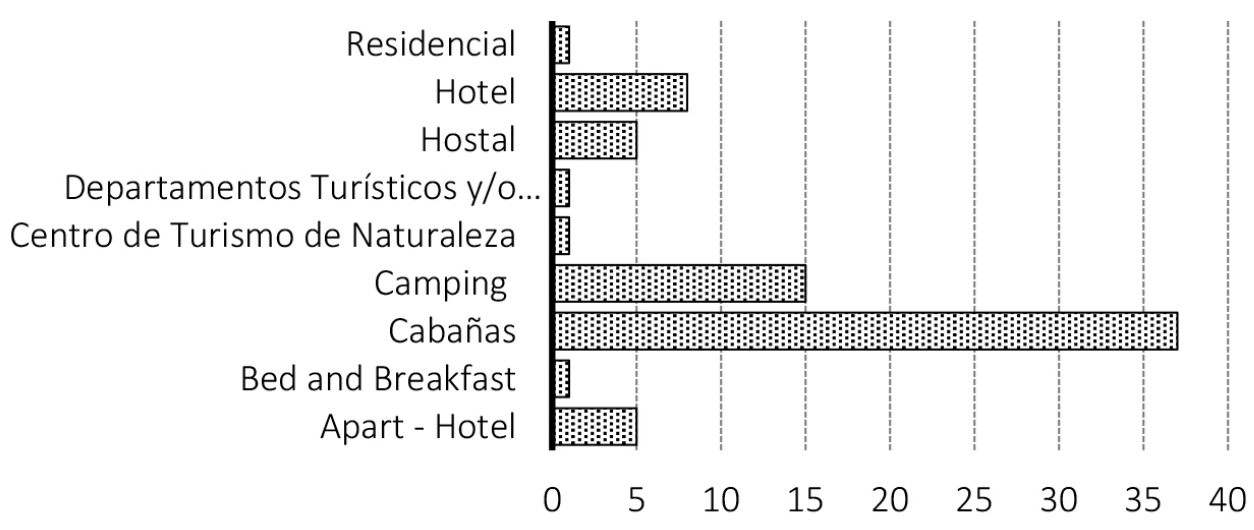

Figura 3. Total de alojamientos según categoría de la Comuna de Paihuano. Elaboración propia, en base a datos del SERNATUR.

El artículo 34 del Sistema Institucional para el Desarrollo del Turismo, dice que: "los prestadores de servicios de alojamiento turístico deberán inscribirse en el Registro" (Ley $\left.N^{\circ} 20423,2010\right)$. A pesar de ello, en la industria del Alojamiento y Hospedaje de la comuna de Paihuano, se pueden identificar las registradas en el Sernatur $(63,6 \%)$ y las que no (36,4\%), situación que podría afectar la calidad del servicio ofrecido al turista. La Figura 4 muestra el total de empresas que se encuentran o no inscritas para las principales localidades de la zona, siendo Alcohuaz la localidad con mayor número de empresas que no cuentan con el registro (11).

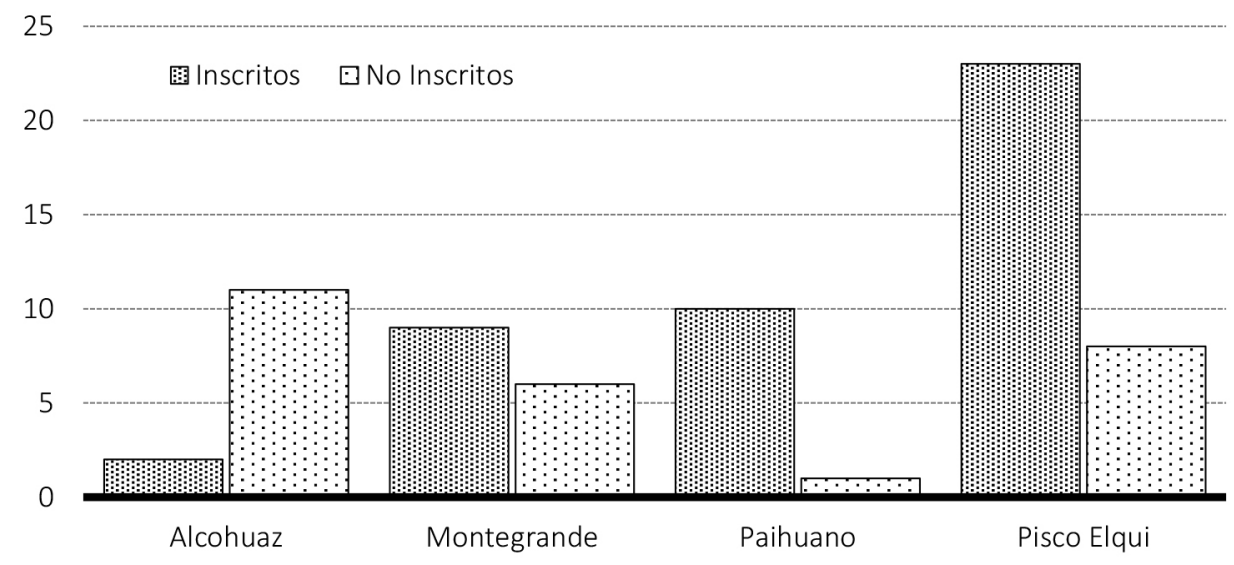

Figura 4. Total de alojamientos de la Comuna de Paihuano, según registro del SERNATUR. Fuente: Elaboración propia. 
- Servicios de gastronomía en la comuna de Paihuano. Los servicios de gastronomía se dividen en tres grupos: restaurantes tradicionales (63,4\%), pequeños establecimientos de venta de comida $(34,2 \%)$ y puestos artesanales de venta de alimentos típicos (2,4\%), to- talizando 41 puestos de servicios en toda la comuna. Similar a lo sucedido con los servicios de alojamiento, Pisco Elqui concentra la mayoría de las ofertas disponibles (75,6\%), seguidas por Paihuano (14,5\%) y Montegrande $(4,9 \%)$.

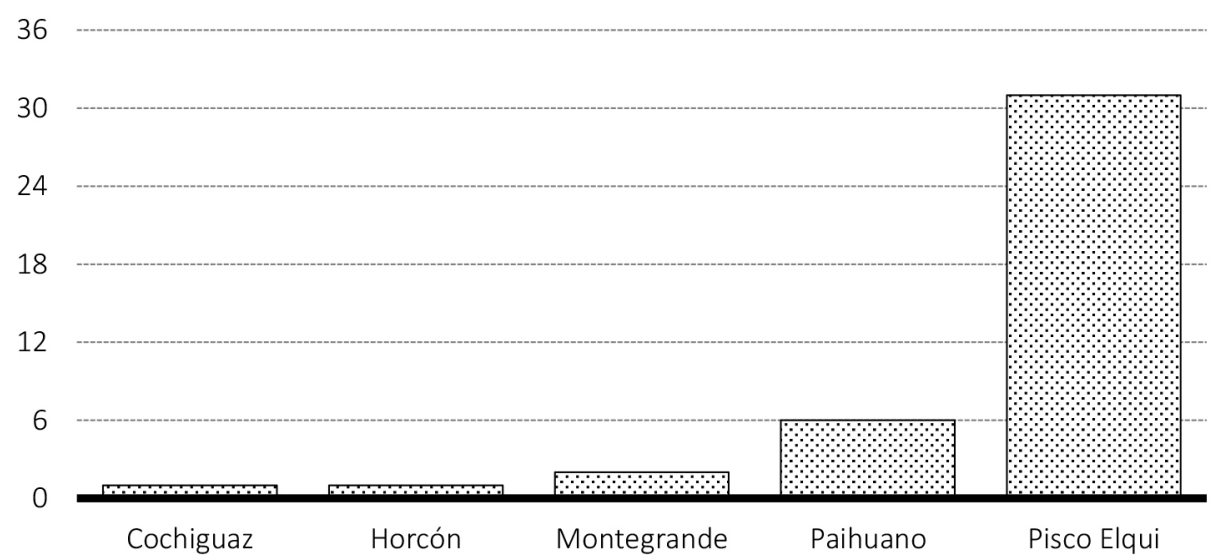

Figura 5. Cantidad de restaurantes y similares en la comuna de Paihuano. Fuente: Elaboración propia.

- Servicios de turismo en la comuna de Paihuano. En la comuna de Paihuano se encuentran pocos servicios de turismo o tour operadores, debido a que la localidad funciona como destino turístico, cuyos ofertantes se ubican principalmente en las ciudades de las comunas colindantes, como la ciudad de La Serena en la capital regional, dada su cercanía al aeropuerto y estación de buses. La Figura 5 resume los servicios de turismo de la comuna de Paihuano.

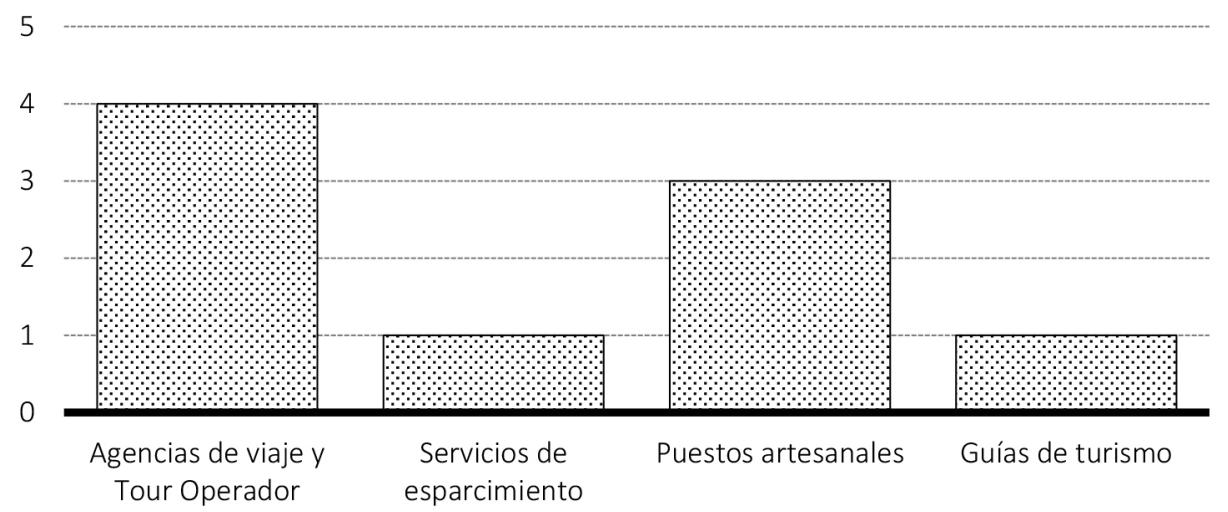

Figura 6. Servicios de turismo de la comuna de Paihuano. Fuente: Elaboración propia. 
- Servicios de atractivos en la comuna de Paihuano (Tabla 2). La comuna de Paihuano se caracteriza por sus atractivos distintivos, históricos y culturales, tales como: las iglesias de Paihuano, Montegrande, Pisco Elqui y Alcohuaz, junto con el museo y mausoleo de Gabriela Mistral en Montegrande. La comuna también destaca por ser el lugar de origen de la producción de pisco. La denominación de origen de este aguardiente de uvas ha logrado fomentar el desarrollo de las distintas pisqueras que se localizan en la comuna, como: Los
Artesanos de Cochiguaz, Pisco Mistral, y Pisco Fundo los Nichos, influyendo directamente en la vida y la cultura de los pobladores de la zona. Además, el Valle de Elqui se exhibe como lugar de cielos limpios e ideales para la investigación astronómica, por lo cual existe la presencia de observatorios distribuidos en todas las localidades como, por ejemplo, el Observatorio Cancana, en la localidad de Cochiguaz, donde se desarrollan tours y charlas con respecto a la astronomía y estudios del cielo nocturno (Figura 7).

Tabla 2. Atractivos de la comuna de Paihuano por categoría, ubicación y la entidad a cargo.

\begin{tabular}{|c|c|c|c|}
\hline Atractivos & Nombre & Ubicación & Entidad a cargo \\
\hline Museo y Mausoleo & $\begin{array}{l}\text { Mausoleo Gabriela Mistral } \\
\text { Museo casa-escuela } \\
\text { Gabriela Mistral }\end{array}$ & $\begin{array}{l}\text { Montegrande } \\
\text { Montegrande }\end{array}$ & $\begin{array}{l}\text { El Consejo de Monumentos } \\
\text { Nacionales (CMN) } \\
\text { El Consejo de Monumentos } \\
\text { Nacionales (CMN) }\end{array}$ \\
\hline Pisqueras y Viñas & $\begin{array}{l}\text { Lagar los Artesanos } \\
\text { de Cochiguaz } \\
\text { Destilería Mistral. } \\
\text { Pisquera los Nichos Limitada } \\
\text { Viña Cavas del Valle }\end{array}$ & $\begin{array}{l}\text { Montegrande } \\
\text { Pisco Elqui } \\
\text { Pisco Elqui } \\
\text { Quebrada de Pinto }\end{array}$ & $\begin{array}{l}\text { Cooperativa Agrícola } \\
\text { Pisquera Elqui Ltda. } \\
\text { Compañía Pisquera de Chile S.A. } \\
\text { Sociedad Agrícola Fundo } \\
\text { Los Nichos S.A. } \\
\text { Cavas del Valle S.A. }\end{array}$ \\
\hline Iglesias & $\begin{array}{l}\text { Iglesia de Paihuano } \\
\text { Iglesia de Montegrande } \\
\text { Iglesia Nuestra Señora del Rosario } \\
\text { Iglesia de Alcohuaz }\end{array}$ & $\begin{array}{l}\text { Paihuano } \\
\text { Montegrande } \\
\text { Pisco Elqui } \\
\text { Alcohuaz }\end{array}$ & $\begin{array}{l}\text { Comunidades } \\
\text { Comunidades } \\
\text { Comunidades } \\
\text { Comunidades }\end{array}$ \\
\hline Observatorios & $\begin{array}{l}\text { Observatorio Cancana } \\
\text { Observatorio Cielo Sur } \\
\text { Elqui Domos }\end{array}$ & $\begin{array}{l}\text { Cochiguaz } \\
\text { Alcohuaz } \\
\text { Pisco Elqui }\end{array}$ & $\begin{array}{l}\text { Camping Refugio Alma Zen } \\
\text { Complejo turístico } \\
\text { Refugios La Frontera } \\
\text { Hotel Astronómico Elqui Domos }\end{array}$ \\
\hline
\end{tabular}

Fuente: Elaboración propia. 


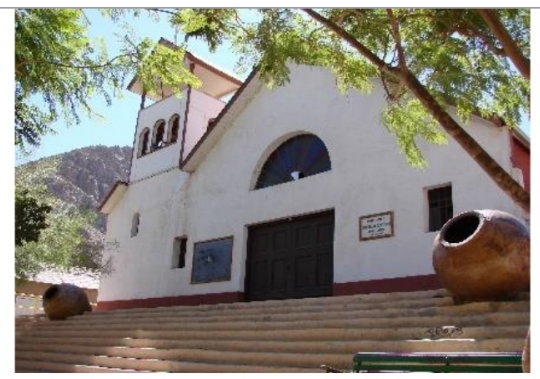

Iglesia de Paihuano

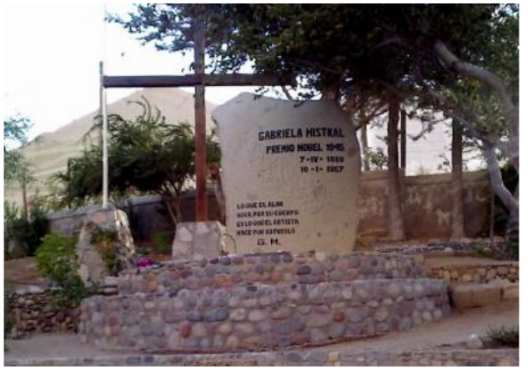

Museo Gabriela Mistral

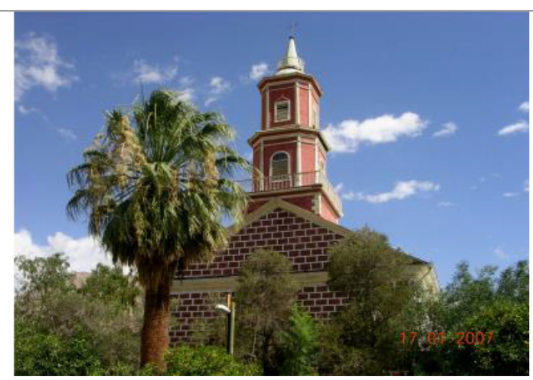

Iglesia de Montegrande

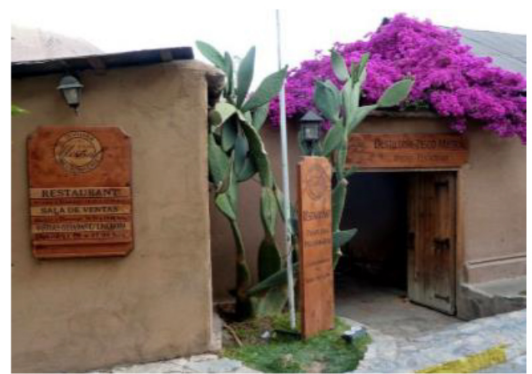

Pisquera Mistral

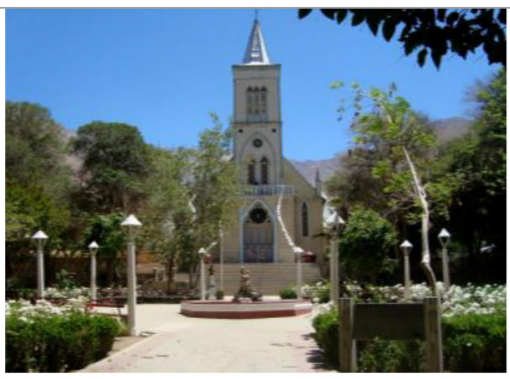

Iglesia de Pisco Elqui

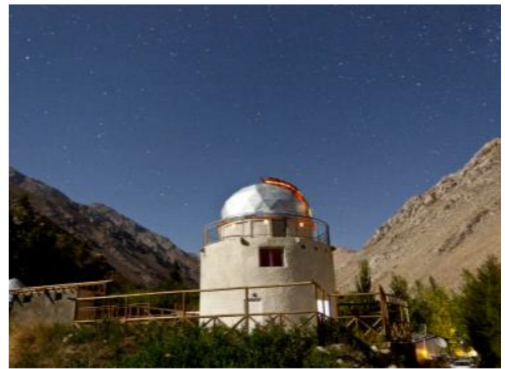

Observatorio cerro Cancana

Figura 7. Fotografías de atractivos turísticos de la comuna de Paihuano. Fuente: http://mapio.net, https://www. tripadvisor.cl y http://www.refugiocochiguaz.cl

- Turismo de intereses especiales en la comuna de Paihuano (Tabla 3): La comuna cuenta con una identidad cultural arraigada en sus costumbres y tradiciones, la cual ha logrado aprovechar para desarrollar el turismo local. Como zona de destino turístico, los poblados cuentan con diversos atractivos propios, que a través de los tours operadores, agencias de viajes y la Municipalidad logran utilizar comercialmente. Además, la localidad cuenta con un favorecido atractivo natural, que brinda la posibilidad de desarrollar numerosos programas turísticos, los cuales se utilizan como medio de atracción para la llegada de nuevos turistas, dándoles sustento a las comunidades más apartadas.

En cuanto al deporte aventura, se realizan actividades como el cicloturismo, cabalgatas y trekking o montañismo, las cuales son impartidas por los tours operadores de varias comunas, y que ocupan la loca- lidad como destino turístico. Los fabricantes de vino y pisco ofrecen rutas turísticas propias para visitar sus plantas de producción, parrones, bodegas, barriles, historias y pequeñas muestras de sus productos, enseñando la tradición detrás del proceso. Esta actividad turística, con un carácter más privado, ha ayudado a los fabricantes locales a exhibir sus productos de una manera activa y personalizada. La vida rural en la localidad es una particularidad propia, debido a su ubicación. En este aspecto, el agroturismo se ha vuelto una actividad importante, combinando el desarroIlo sustentable con la actividad turística, actualmente la comunidad mapuche Canihuante de Cochiguaz desarrolla esta actividad. En el área del bienestar y la salud, la comuna cuenta con centros de relajación y spa, los cuales complementan la identidad de tranquilidad y relajación que turistas logran encontrar al llegar a la comuna. 
Tabla 3. Turismo de intereses especiales en la comuna de Paihuano.

\begin{tabular}{ll}
\hline Atractivos & Categorías \\
\hline Aventura y deporte & Cabalgatas \\
& Turismo astronómico \\
& Rutas de trekking \\
& Excursiones en bicicleta \\
& Programas turísticos \\
\hline Cultura y patrimonio & Visitas guiadas a las Iglesias \\
& Visitas al museo y mausoleo de Gabriela Mistral \\
& Aniversario de Paihuano (16/Dic) \\
& Celebración de la Virgen del Rosario \\
& Fiesta costumbrista de Paihuano \\
& Fiesta de la Vendimia de Valle del Elqui \\
\hline Pisqueras y Viñas & Celebración del Año Nuevo de Pueblos Originarios \\
& Lagar los artesanos de Cochiguaz \\
Vida rural & Destilería Mistral \\
Bienestar y salud & Pisquera los Nichos Limitada \\
\hline
\end{tabular}

Fuente: Elaboración propia.

- Transporte, información y viabilidad. Actualmente existen dos servicios de transporte que llegan a la localidad: buses y taxis colectivos; los buses son el medio más utilizado. Sus recorridos, que atraviesan todo el Valle de Elqui, incluyen a Coquimbo, La Serena, Vicuña, Paihuano y Pisco Elqui, en un tiempo aproximado de 2 horas 30 minutos. En la plaza de Pisco Elqui se ubica el único puesto de información turística que dispone el Municipio. En él se entregan datos de la comuna, en cuanto a sus diversos atractivos, operadores turísticos, alojamientos y gastronomía. La localidad cuenta con una infraestructura vial de pocos y estrechos caminos, con servicios de estacionamientos, que son fundamentales para contrarrestar la congestión vehicular en épocas de alta afluencia de turistas.

\section{Aceptación del cicloturismo como producto turístico para la Comuna}

Las localidades rurales de Paihuano son pueblos con costumbres y tradiciones ancestrales. Las sucesivas generaciones de sus habitantes han observado como la actividad turística se ha ido arraigando en su cultura y forma de vida, siendo un factor determinante en la evolución de su identidad y componente clave del desarrollo y progreso de su gente.

El reconocimiento de la relevancia del turismo como una fuente de crecimiento económico y social para la comuna, es requisito fundamental para instaurar cualquier producto turístico exitosamente en la zona. Por ello, se recolectó el testimonio de tres representantes claves y actores influyentes para su desarrollo (alcalde de la comuna, director de SERNATUR y principal operador turístico de la comuna), los cuales se detallan a continuación:

- Para la máxima autoridad comunal, el cicloturismo es una actividad que se tiene considerado desarrollar en su plan de trabajo, pero que dada las condiciones económicas en las cuales se mantiene la Municipalidad han debido priorizarse otros proyectos. Además, el edil indica que el cicloturismo es una actividad con gran potencial de desarrollo en la zona, pero que presenta limitantes que deben resolverse para lograr su 
ejecución plena, tales como el acceso a información clara, perfeccionamiento de caminos, senderos y puntos de accesibilidad, la instauración de controles de seguridad, y mejorar la calidad de las bicicletas, además de potenciar la coordinación con privados para crear nuevas rutas recreativas y culturales, entre otros aspectos. También declaró que esta actividad se debería coordinar a través de la Municipalidad y empresarios turísticos, para generar un plan de desarrollo estratégico que permita aprovechar íntegramente los atractivos turísticos de la comuna.

- Para el principal operador turístico de la comuna y único oferente de la actividad en Pisco Elqui, el cicloturismo es una actividad atrayente para el turista que visita la localidad, pero que faltan los caminos, accesos, o información necesaria para que éstos puedan recorrer libremente las diferentes localidades y sus atractivos (cicloturismo auto-guiado). Estas restricciones, señala, son las que explican que el potencial de la actividad se vea mermado y que disminuya el interés del sector privado por brindar de manera abierta el servicio guiado o con información de rutas culturales o patrimoniales, limitándose solo a ofrecer el servicio de arriendo de bicicletas y dejando a discreción del turista su recorrido por la zona.

- Para el director de SERNATUR de la Región de Coquimbo, la comuna de Paihuano tiene un posicionamiento arraigado a nivel nacional y uno creciente a nivel internacional, lo que le depara es una gran proyección a mediano y largo plazo, para lo cual es fundamental que los servicios turísticos presentes en la comuna tengan los estándares de calidad exigidos por el mercado. Señala como ejemplo, que actualmente solo una empresa está certificada por Sernatur para realizar cicloturismo como actividad de deporte aventura, pero que existen otras empresas que ofrecen el servicio de arriendos de bicicletas, las cuales pueden evadir la norma ofreciendo rutas guiadas. Además, de no existir un control de calidad de las bicicletas que se arriendan (como, por ejemplo: sistema de frenos, cascos y accesorios complementarios de seguridad), se pone en riesgo la seguridad de los propios turistas. Para SERNATUR, ésta es una actividad atractiva para los turistas que visitan la comuna, además es parte de una tendencia y cultura creciente que tiene los distintos usos de la bicicleta, lo cual ha ido avanzando cada vez más y es importante para una localidad con tanta influencia turística ir a la par con estas nuevas co- rrientes, pero sin perder la identidad cultural que conlleva la comuna de Paihuano.

- Por último, se realizó un grupo focal con un club de ciclistas destacado de la región de Coquimbo. Éstos plantearon que, si bien la comuna de Paihuano cuenta con un clima y paisajes privilegiados para practicar este deporte, además de tener ese atractivo místico que encanta a las personas que la visitan, aun no existe una infraestructura pensada para los ciclistas, como paraderos con agua, señaléticas con información turística, ciclovías señalizadas, estacionamientos para bicicletas, talleres mecánicos, lugares para venta de accesorios y repuestos. Entre las condiciones necesarias para mejorar el atractivo de la actividad, destacaron la educación y promoción de los grandes beneficios que conlleva practicar la actividad.

De las entrevistas se desprende que el cicloturismo se percibe como una actividad que ha venido en alza en los últimos años y que cada vez toma más fuerza como alternativa turística para lugares con atractivos naturales, culturales y patrimoniales destacados. Sin embargo, a pesar de gozar de este buen nivel de aceptación, el análisis de los resultados, permite evidenciar que para que el cicloturismo pueda ser considerado como una opción viable a las demás actividades turísticas ofrecidas en la comuna de Paihuano, requiere:

- Establecer rutas para ciclistas, las cuales permitan al visitante recorrer de forma expedita y sin peligro la carretera;

- Implementar señaléticas para los cicloturistas, que indiquen claramente a qué lugar lleva cada ruta, cuál es su distancia, y los principales atractivos que se pueden encontrar. Según las encuestas realizadas la mayoría de los turistas prefieren desarrollar esta disciplina sin guía (cicloturismo auto-guiado), por lo que la información entregada y las señaléticas son fundamentales para que las personas que practiquen el cicloturismo sin inconvenientes;

- Potenciar los servicios de apoyo al cicloturismo, instaurando guías y paneles informativos (en más de un idioma), que describan los atractivos que la comuna de Paihuano tiene para visitar, las rutas de acceso, los horarios de atención, las formas de llegar, etc.; 
- Desarrollar programas sociales dirigidos a la comunidad y los empresarios que busquen, por una parte, crear una cultura turística que concientice sobre los distintos beneficios que, el turismo trae para la comuna y el país, y por otra, desarrollar las competencias y habilidades de los empresarios responsables de las actividades relacionadas con la ruta turística, mediante cursos y talleres de capacitación;

- Generar una red público - privada, en colaboración y apoyo a la actividad turística vinculada al cicloturismo. De esta red se espera surjan iniciativas para el apalancamiento de recursos que generen un destino competitivo e innovador;

- Implementar herramientas de marketing digital (páginas Web, aplicaciones móviles, blogs, etc.) para promocionar los destinos turísticos de la Comuna, sus atractivos naturales, culturales y/o patrimoniales. Esto representa un desafío mayor, tanto para los destinos como para las empresas turísticas, dar acceso a puntos Wi-Fi a quienes los visitan.

\section{CONCLUSIONES}

El planteamiento de modelos turísticos sostenibles en áreas que tradicionalmente se han dedicado a otras actividades económicas, hace imperativo que se analicen, con detalle, los factores determinantes para su adecuada implementación y práctica. En este trabajo se ha abordado un examen del potencial de desarrollo del cicloturismo en el norte de Chile, específicamente, en las localidades rurales de la comuna de Paihuano, Valle de Elqui, IV Región de Coquimbo.

Los resultados demostraron que la comuna de Paihuano reúne las condiciones naturales, los servicios suplementarios y cuenta con el nivel de aceptación apropiado del turista para desarrollar el cicloturismo como una opción potencial del turismo sustentable para las localidades rurales de la comuna de Paihuano, Valle de Elqui, Chile.

Sin embargo, se reconoce que para ser considerada una opción viable a las demás actividades turísticas ofrecidas en la zona, requiere de un mayor nivel de compromiso y apoyo de parte de las autoridades en la promoción de la cultura turística de la localidad, así como mejorar la infraestructura e información necesaria para su práctica (ciclovías, señaléticas, tableros informativos con las rutas, entre otras) y la comunicación pública-privada entre los actores relevantes. Entender el cómo trabajan y se complementan los distintos servicios turísticos de la comuna de Paihuano es fundamental para conocer la influencia que tiene cada uno de ellos en el desarrollo turístico, económico y social de la localidad.

Tal como señalan Orozco \& Núnez (2013), debe además tenerse presente, respaldar las políticas y acciones propuestas con el diseño de un modelo de desarrollo local territorial, construido con la participación de todos los actores sociales involucrados en las dimensiones ambiental, económica, social y cultural, y política, donde se podría aspirar a que la actividad turística de la Comuna de Paihuano lograra beneficios que impactaran de manera equitativa a la comunidad local y en la preservación del ambiente y el patrimonio natural.

\section{REFERENCIAS}

Aragoneses Maroto, J. P. (2010). Cicloturismo base en la provincia de Segovia: itinerarios sencillos y familiares. Madrid, España: Caja de Ahorros y Monte de Piedad de Segovia.

Biblioteca del Congreso Nacional. (2015). Reporte Estadístico Comunal 2015 Paihuano. Santiago: Biblioteca del Congreso Nacional de Chile. Recuperado a partir de http://reportescomunales.bcn.cl/2015/ PDF/Paihuano.pdf.

Casas Manríquez, P. M. (2004). Bases técnicas para la implementación de una red de turismo rural en el complejo Malleco-Tolhuaca, IX Región (Tesis de pregrado). Santiago, Chile: Universidad de Chile. Recuperado a partir de http://repositorio.uchile. cl/bitstream/handle/2250/105045/casas_p.pdf?sequence $=3 \&$ isAllowed $=y$

Cherni, J. A. (2001). EURE (Santiago). EURE (Santiago), 27(81), 25-41. https://doi.org/10.4067/S025071612001008100002

La Covarrubias Ramírez, R., Vargas Vásquez, A., \& Rodríguez Herrera, I. (2010). Satisfacción de residentes con el desarrollo de la actividad turística en los Pueblos Mágicos de México: Un indicador de competitividad. casos de Comala en Colima y de real de asientos en Aguascalientes. Gestión Turística, 14, 33-54. Recuperado a partir de http://www. redalyc.org/articulo.oa?id=149213727009 
Cox, P. (2013). The paradoxes of cyclotourism: Constructing and consuming nature. En 7th Biennial European Society for Environmental History conference - Circulating natures: Food-water-energy. Munich, Alemania: Ludwig Maximillian University in Munich.

Díaz Ortega, F. V. (2004). Propuesta de estrategia local de reciclaje para los residuos sólidos domiciliarios de la comuna de Paihuano, IV Región de Coquimbo (Tesis de pregrado). Santiago, Chile: Universidad de Chile. Recuperado a partir de http://repositorio. uchile.cl/bitstream/handle/2250/101741/diaz_f. pdf?sequence $=4$

Eltit Neumann, V. (2011). Transporte urbano no motorizado: El potencial de la bicicleta en la ciudad de Temuco. Revista INVI, 26(72), 153-184. https://doi. org/10.4067/S0718-83582011000200006

Espinosa, A., Llancaman, L., \& Sandoval, H. (2014). Turismo de intereses especiales y parques nacionales. Estudios y perspectivas del Turismo, 23(1), 115-130. Recuperado a partir de http://www.redalyc.org/articulo.oa?id=180729920007

Gannon, A. (1994). Rural tourism as a factor in rural community economic development for economies transition. J. Sustain. Tourism, 1(1-2), 51-60.

García, J. . (1996). El Turismo Rural como factor diversificador de rentas en la tradicional economía agraria. Estudios Turísticos, 122, 45-59.

Gonçalves-Junior, L., Corrêa, D. A., da Silva Carmo, C., \& Toro Arévalo, S. (2016). Diarios de bicicleta : procesos educativos vivenciados en la Ruta de las Emociones. Estudios Pedagógicos, 42(1), 323-337. https://
doi.org/10.4067/S0718-07052016000100021

Gozner, M. (2015). Solutions for the Development of Leisure Tourism By Specific Arrangements (Cyclotourism) in the Albac - Arieșeni Territorial System (Alba County, Romania). GeoJournal of Tourism and Geosites, 15(1), 59-66.

Herrera, P., \& Cortés, I. (2006). Propuesta de rutas cicloturísticas para el desarrollo del ecoturismo aplicado en la Provincia del Elqui (Tesis de pregrado). La Serena, Chile: Universidad de La Serena.

Ilieș, D., Herman, G., Dehoorne, O., \& Măduța, F. (2013). The role and the importance of cyclotourism in the development of the Oradea Metropolitan Area (Romania). GeoJournal of Tourism and Geosites, 12(2), 101-110.

Ley N²0423. (2010). Diario Oficial de la República de Chile. Santiago, Chile. Recuperado a partir de https:// www.sernatur.cl/transparencia/archivos/marco-normativo/marco-norm-aplic/LEY-20423-modificada.pdf

Maráková, V., \& Medved'ová, M. (2016). Innovation in Tourism Destinations. Forum Scientiae Oeconomia, 4(1), 33-43. https://doi.org/10.1300/J162v06n03

Mató, E., \& Troyano, X. (2014). El impacto económico del cicloturismo en Europa. Síntesis de los principales estudios realizados (Primera ed). Consejería de Fomento y Vivienda de la Junta de Andalucía. Recuperado a partir de https://viasverdes.com/ prensa/documentos/interes/Informe_Cicloturismo_2014.pdf

Matthews, C. E., Jurj, A. L., Shu, X. O., Li, H. L., Yang, G., Li, Q., ... Zheng, W. (2007). Influence of exercise, 
walking, cycling, and overall nonexercise physical activity on mortality in Chinese women. American Journal of Epidemiology, 165(12), 1343-1350. https://doi.org/10.1093/aje/kwm088

Moral, M. M. (2016). La puesta en valor de un recurso turístico cultural sostenible en el medio rural: El caso de las Vías Verdes en España. María Moral Moral, 12(2), 161-175.

Morère Molinero, N., \& Perelló Oliver, S. (2013). Turismo Cultural, patrimonio, museos y empleabilidad. Guia del lector. Madrid: Fundación EOI. https://doi. org/10.11606/issn.1984-4867.v25i2p497-499

Noguera, J. (Editor). (2016). La visión territorial y sostenible del desarrollo local: una perspectiva multidisciplinar. Valencia, España: Universitat de València.

Orozco, J., \& Núnez, P. (2013). Las teorías del desarrollo. En el analisis sustentable. Intersedes: Revista de las sedes regionales, XIV(27), 144-167. Recuperado a partir de http://www.redalyc.org/articulo. oa?id=66627452008

Puccio, H., \& Grana, N. (2008). La innovación como requisito para la competitividad turística: Una metodología para su descripción y análisis. Gestión Turística, 10, 59-76. https://doi.org/10.4206/gest. tur.2008.n10-05

Ramírez González, A., \& Domínguez Calle, E. A. (2011). El Ruido Vehicular Urbano: Problemática Agobiante De Los Países En Vías De Desarrollo. Revista de la Academia Colombiana de Ciencias Exactas, Físicas y Naturales, 35(137), 509-530. Recuperado a partir de http://www.scielo.org.co/scielo.php?script=sci_arttext\&pid=S0370-39082011000400009\&ln- g=en\&nrm=iso\&tlng=es

Santana Talavera, A. (2003). Turismo cultural, culturas turísticas. Horizontes Antropológicos, 9(20), 31-57. https://doi.org/10.1590/S010471832003000200003

Servicio Nacional de Turismo. (2014). Turismo cultural: Una oportunidad para el desarrollo local. Guía Metodológica (Primera ed). Santiago, Chile: Servicio Nacional de Turismo. Recuperado a partir de https:// www.sernatur.cl/wp-content/uploads/2017/05/ Guía-Turismo-Cultural_Chile-México.pdf

Szmulewicz, P. R., \& Veloso, K. M. (2013). Oportunidades Y Desafíos De La Investigación en Turismo en Patagonia. Anales Instituto Patagonia (Chile), 41(2), 29-41. Recuperado a partir de http://www.scielo. $\mathrm{cl} / \mathrm{pdf} /$ ainpat/v41n2/art02.pdf

UNEP-WTO. (2005). Making tourism more sustainable. A guide for policy makers (Vol. 54). París, Francia: UNEP \& WTO. Recuperado a partir de http:// www.unep.fr/shared/publications/pdf/dtix0592xpa-tourismpolicyen.pdf

Verheugen, G. (2005). A renewed EU Tourism Policy: Towards a stronger partnership for European Tourism. En Commission of the European Communities (pp. 1-6). Malta: 4th European Tourism Forum. Recuperado a partir de http://europa.eu/rapid/ press-release SPEECH-05-626 en.pdf

Zovko, I. (2013). The Value of Cycle Tourism Opportunities for the Scottish economy. Transform Scotland. Recuperado a partir de http://transformscotland. org.uk/wp/wp-content/uploads/2014/12/TheValue-of-Cycle-Tourism-full-report.pdf 